\title{
Estudo Propositivo para Aprendizagem Significativa das Equações Algébricas do Primeiro Grau Através do Scratch
}

\section{Propositive Study for Meaningful Learning of First-Degree Algebraic Equations through Scratch}

\author{
Mariana Oliveira Puccia ${ }^{a}$; Janice Teresinha Reichert*b
}

\author{
${ }^{a}$ Universidade Federal da Fronteira Sul, Programa de Pós-Graduação Stricto Sensu em Matemática em Rede. SC. Brasil \\ bUniversidade Federal da Fronteira Sul. SC, Brasil. \\ *Email: janice.reichert@uffs.edu.br
}

\begin{abstract}
Resumo
A compreensão da variável algébrica tem sido amplamente discutida, com diferentes populações e através de diferentes ferramentas. No entanto, há poucos estudos investigando a sua abordagem através do uso de recursos computacionais. Neste sentido, este trabalho avalia as contribuições da linguagem de programação Scratch na aprendizagem significativa das equações algébricas do $1^{\circ}$ grau. O estudo de caso foi realizado com estudantes regularmente matriculados no $8^{\circ}$ ano de uma escola da rede estadual em Lages - SC. As atividades propostas, desenvolvidas nas aulas de Matemática, corresponderam a 10 encontros num total de 16 horas. Para a coleta de dados, foi utilizada uma investigação qualitativa com a aplicação de testes antes e após as intervenções, sobre conhecimentos prévios relacionados às equações algébricas do $1^{\circ}$ grau e lógica de programação, e adquiridos durante o desenvolvimento das atividades. O software Scratch foi apresentado como uma ferramenta de auxílio na resolução de problemas algébricos e os estudantes incentivados a construírem seus próprios projetos utilizando a linguagem de programação. Observou-se que, neste cenário o Scratch auxilia a suprir as dificuldades dos educandos em relação ao conteúdo de Equações Algébricas do $1^{\circ}$ grau, tornando o aprendizado do conceito de variável algébrica mais significativo.
\end{abstract}

Palavras-chave: Aprendizagem Significativa. Matemática. Construcionismo.

\begin{abstract}
The understanding of the algebraic variable has been widely discussed, with different populations and through different tools. However, there are few studies investigating its approach through the use of computational resources. In this sense, this work assesses the contributions of the Scratch programming language in the meaningful learning of the algebraic equations of the 1st degree. The case study was carried out with students regularly enrolled in the 8th grade of a state school in Lages - SC. The proposed activities, developed in mathematics classes, corresponded to 10 meetings in a total of 16 hours. For data collection, a qualitative investigation was adopted with the application of tests before and after the interventions, on previous knowledge related to the algebraic equations of the 1st degree and programming logic and acquired during the development of the activities. The Scratch software was presented as an aid tool in solving algebraic problems and students were encouraged to build their own projects using the programming language. It was observed that, in this scenario, Scratch helps to solve the difficulties of the students in relation to the content of Algebraic Equations of the 1st degree, making the learning of the concept of algebraic variable more significant.
\end{abstract}

Keywords: Meaningful Learning. Mathematics. Constructionism.

\section{Introdução}

Segundo Da Costa, De Azevedo, Rodrigues, Hauschild \& Dullius, M. M. (2018) a maioria dos estudantes apresentam dificuldades em compreender os problemas relacionados ao conteúdo de Álgebra. A dificuldade de compreensão se potencializa com a introdução de incógnitas aos cálculos relacionados às equações, que se dá no $7^{\circ}$ ano do Ensino Fundamental.

As dificuldades em interpretar os diferentes papéis das variáveis algébricas também são relatadas em trabalhos como (Knuth, Alibali, Mcneil, Weinberg \& Stephens, 2005; Tahir, Cavanagh \& Mitchelmore, 2009; Pedersen, 2015; Warren, Trigueros \& Ursini, 2016; Ursini, 2019).

Estas dificuldades apresentadas na aprendizagem da Álgebra levam a repensar e a querer buscar estratégias para o ensino deste conteúdo. Nesse sentido, a linguagem de programação Scratch $^{1}$ apresenta-se como uma alternativa no processo de ensino e aprendizagem, por não exigir conhecimento de outras linguagens de programação, por ser ideal para pessoas que estão começando a programar, por ter sido desenvolvido para ajudar estudantes acima de 8 anos no aprendizado de conceitos matemáticos e computacionais e, principalmente por despertar o interesse e a curiosidade. Com ela é possível criar histórias animadas, jogos e outros programas interativos, ou seja, pode ser uma ferramenta no auxílio do desenvolvimento da lógica de programação e no processo de entendimento significativo da variável algébrica presente nas equações algébricas do $1^{\circ}$ grau.

O Scratch é utilizado desde o Ensino Fundamental até o Universitário. Estudos de Aono, Rody, Musa, Pereira \&

1 https://scratch.mit.edu/ 
Almeida (2017) mostram que a utilização do Scratch, no Ensino Fundamental, envolve abordagens práticas sem a necessidade de explicações mais teóricas sobre os conteúdos utilizados na construção das animações. No Ensino Médio, as aulas teóricas e as discussões a respeito do conteúdo de programação podem ser auxiliadas pelo uso do Scratch. E no Ensino Superior, tem tornado o ensino de programação acessível e menos traumático aos estudantes.

No ensino da Matemática, Oliveira (2009) esclarece sobre o uso do Scratch e a possibilidade de incorporação curricular como uma ferramenta no processo de ensino e aprendizagem. Considera o Scratch uma ferramenta eficiente, por ser intuitivo ajuda no desenvolvimento de conteúdos programáticos e extras no ambiente escolar, podendo ser utilizado desde suas aplicações básicas, como jogos simples, até algo mais elaborado como o trabalho com variáveis e elementos que envolvem lógica Matemática e computacional.

Zoppo (2016) busca compreender como os estudantes do $5^{\circ}$ ano do Ensino Fundamental interagem com um objeto de aprendizagem desenvolvido no Scratch para o ensino de sistemas de medidas de comprimento. Esta pesquisa identificou no Scratch, duas possibilidades para a construção do conhecimento matemático: uma delas é que o ambiente proporciona ao estudante a criação de projetos de seu interesse como: jogos, cartões animados e histórias interativas; e a segunda é a possibilidade de o professor utilizá-lo como um material didático digital.

Ainda, por proporcionar um ambiente em que os estudantes possam aprender através da construção do seu próprio conhecimento e por possibilitar que eles criem animações partindo da sua realidade, tem-se que o Scratch é uma ferramenta que permite a utilização de uma metodologia construcionista, conforme proposto por Papert (1993), para uma possível aprendizagem significativa (Ausubel, 1963).

A principal característica do construcionismo é a utilização da tecnologia como uma ferramenta que auxilie os estudantes a construir o seu próprio conhecimento. O computador nessa proposta se torna um recurso auxiliar na busca de novas informações, procurando priorizar o interesse e estilo cognitivo do aprendiz (Papert, 1980).

Neste contexto, o docente tem a oportunidade de acompanhar o raciocínio que o estudante está utilizando para realizar determinada atividade. E assim, poderá ajudálo a interpretar as respostas por ele encontradas e questionálo sobre o seu processo mental para que possa compreender o que está estudando e ampliar o seu conhecimento sobre o assunto.

Segundo Papert (1993) os computadores devem servir às crianças como instrumentos para trabalhar e pensar, como meios para realizar projetos, como fonte de conceitos para pensar novas ideias. Neste sentido entende-se que o software Scratch, que é uma ferramenta de linguagem de programação, cuja pioneira foi a linguagem Logo, está alinhado a esta concepção e pode ser muito útil na aprendizagem do conceito de equações algébricas do $1^{\circ}$ grau por proporcionar um ambiente interativo no qual o estudante pode realizar projetos, criar e estabelecer novas ideias.

A aprendizagem significativa de Ausubel (1963) prevê a necessidade do aprendiz se colocar como sujeito ativo e não passivo em seu processo de aprendizagem e que o mesmo possui algum conhecimento prévio, que precisa ser considerado. Essa teoria defende que não se deve considerar o estudante como um livro em branco, como uma tábula rasa, mas sim, como alguém que já adquiriu algum conhecimento e os novos que devem ser ensinados a ele, devem ser ancorados aos conhecimentos que ele já possui. A nova informação se relaciona com um aspecto relevante da estrutura de conhecimento do indivíduo, ou seja, interage com uma estrutura de conhecimento, a qual Ausubel (1963) define como subsunçor.

Ausubel (1963) recomenda o uso de organizadores prévios, que sirvam de âncora para a nova aprendizagem e levem ao desenvolvimento de conceitos subsunçores que facilitem a aprendizagem subsequente. Organizadores prévios são materiais introdutórios apresentados antes do próprio material a ser aprendido. A principal função destes é a de servir de ponte entre o que o aprendiz já sabe e o que deveria saber, a fim de que o material possa ser aprendido de forma significativa.

$\mathrm{O}$ autor distingue a aprendizagem significativa de três maneiras: Aprendizagem Significativa Representacional, Aprendizagem Significativa de Conceitos e Aprendizagem Significativa Proposicional. A primeira, é o tipo mais básico de aprendizagem significativa, do qual as demais dependem e envolve a atribuição de significados a determinados símbolos. A segunda, também se relaciona com a representacional e nela os símbolos representam regularidades em eventos ou objetos. E a terceira refere-se a aprender o significado das ideias expressas verbalmente através de conceitos sob forma de proposição.

As três distinções podem ser relacionadas ao objeto de conhecimento de Equações Algébricas pois, os estudantes precisam saber o significado dos símbolos ou das letras que normalmente são utilizadas, eles também precisam entender qual o significado das regularidades apresentadas e não menos importante que isso, eles precisam relacionar as ideias que essas expressões apresentam.

Segundo Ausubel (1968, p.41), "a essência do processo de aprendizagem significativa é que ideias simbolicamente expressas sejam relacionadas de maneira substantiva (não literal) e não arbitrária ao que o aprendiz já sabe", ou seja, há algum aspecto de sua estrutura cognitiva especificamente relevante para a aprendizagem dessas ideias.

As Equações Algébricas envolvem números e símbolos além de um significado que por vezes passa despercebido aos estudantes. Isso acontece, possivelmente, devido à falta de 
entendimento deste conteúdo quando relacionado ao cotidiano. E é nesse contexto que a Aprendizagem Significativa deve ser utilizada, pois dar significado às ideias, aos conceitos, aos símbolos e às proposições pode ser uma maneira de fazer com que esse conteúdo seja mais significativo ao estudante.

Neste trabalho propõe-se como ponto de partida problemas do cotidiano dos estudantes, definidos a partir do questionário diagnóstico inicial. Além disto, utiliza-se os princípios da Aprendizagem Significativa estabelecendo conexões dos novos conteúdos com os que o estudante já possui, através dos organizadores prévios. O objetivo é avaliar as contribuições do Scratch, através de uma metodologia construcionista, na aprendizagem significativa das equações algébricas do $1^{\circ}$ grau, para estudantes do $8^{\circ}$ ano de uma escola pública em Lages-SC.

\section{Material e Métodos}

\subsection{Objeto da pesquisa}

O estudo de caso foi realizado com estudantes regularmente matriculados em uma turma de $8^{\circ}$ ano de uma escola da rede estadual de Lages - SC.

Num primeiro momento aplicou-se um questionário diagnóstico, visando entender a realidade dos estudantes e um pré-teste, para investigar as dificuldades relacionadas a interpretação de problemas e da variável algébrica, no objeto de conhecimento de Equações algébricas do $1^{\circ} \mathrm{Grau}$ e, os conhecimentos prévios sobre lógica de programação. Após, realizou-se uma intervenção na turma, com a introdução do Scratch, buscando aliar o seu uso ao processo de implementação computacional de situações-problema. Por fim, os estudantes responderam um pós-teste com o objetivo de verificar a aprendizagem significativa do conceito de variável algébrica.

A aplicação das atividades ocorreu durante os meses de março até junho de 2019, no horário das aulas de Matemática, utilizando 10 encontros num total 16 horas.

\subsection{Caracterização do público}

A turma constitui-se de 28 estudantes, sendo 13 meninas e 15 meninos, com idades variando entre 13 e 16 anos. A escola se localiza na região urbana de Lages e atende estudantes desde o $1^{\mathrm{o}}$ ano do Ensino Fundamental até a $3^{\mathrm{a}}$ série do Ensino Médio. A estrutura física da escola é boa, com biblioteca e sala de multimídia, porém, possui laboratório de informática com 8 computadores e destes apenas 3 tinham acesso à internet.

\subsection{Dinâmica da proposta}

Trata-se de uma pesquisa-ação qualitativa através de um estudo de caso, realizada por meio de questionários (chamados de pré e pós-testes) e intervenção na turma.

Devido à escassez de computadores, a turma teve que ser dividida em dois grupos e a temática repetida, totalizando desta forma 10 encontros num total de 16 horas para cada grupo, que foi constituído por no máximo 15 estudantes. Desta forma, quando um grupo participava das atividades o outro permanecia em sala de aula com a professora de Matemática. Em alguns encontros foram necessárias mais de duas aulas com cada grupo para o desenvolvimento de uma atividade.

No primeiro encontro ocorreu o detalhamento do projeto, após a apresentação do programa e, quando os estudantes já estavam mais familiarizados com o ambiente, propôs-se que os mesmos elaborassem, no Scratch, resolução de três situações problemas, destas duas foram escolhidas previamente pelo professor/pesquisador e a última foi determinada pelos próprios estudantes e utilizada para execução do projeto final.

\subsection{Coleta de dados}

A coleta dos dados ocorreu por meio de observação, registro em diário de bordo, fotos, análise dos materiais preenchidos pelos estudantes (questionário, pré-teste e pósteste) e ainda pelo desenvolvimento de um projeto final. $\mathrm{O}$ questionário diagnóstico inicial foi constituído por questões direcionadas a identificação de características dos estudantes, ao meio em que eles vivem e a sua vida escolar. Os pré e pós testes possuíam cinco questões descritivas voltadas diretamente ao conteúdo de Equações Algébricas do $1^{\circ}$ grau e seis questões relacionadas a lógica de programação, sendo cinco objetivas e uma descritiva.

As questões do pós-teste e a proposição de desenvolvimento do projeto final foram elaborados para contemplar a análise da Aprendizagem Significativa, pois segundo Moreira e Masini (1982) ao se procurar evidência de compreensão significativa, a melhor maneira de evitar a "simulação da aprendizagem significativa" é utilizar questões e problemas que sejam novos e não familiares e requeiram máxima transformação do conhecimento existente. Ainda, testes de comparação devem ser fraseados de maneira diferente e apresentados num contexto de alguma forma diversa daquele originalmente encontrado no material instrucional.

O projeto final, desenvolvido pelos estudantes, buscou utilizar a lógica de programação para um melhor entendimento da variável algébrica e corrobora para a avaliação da aprendizagem significativa, pois, conforme Moreira \& Masini (1982), uma outra alternativa para testar a ocorrência da aprendizagem significativa é a de propor ao aprendiz uma tarefa de aprendizagem, sequencialmente dependente da outra, que não possa ser executada sem o perfeito domínio da precedente. Além disto, na construção do projeto final os estudantes foram incentivados a autonomia e detecção de seus acertos e erros, num processo contínuo de aprendizagem.

\subsection{Desenvolvimento das atividades}

Para a elaboração da sequência didática e do material de ensino, levou-se em consideração a teoria de Ausubel: "o material a ser assimilado seja potencialmente significativo, ou seja, não arbitrário em si” e "mesmo materiais arbitrários então, 
podem ser tornados significativos através de Organizadores Prévios" (Ausubel, 1968, p.37). Na sequência detalha-se o desenvolvimento das atividades.

$1^{\circ}$ encontro: Explicação do projeto e entrega do Termo de Consentimento Livre e Esclarecido

$2^{\circ}$ encontro: Aplicação do questionário diagnóstico inicial e do pré-teste

O objetivo do pré-teste foi verificar os conhecimentos prévios sobre a lógica de programação, especificamente a linguagem Scratch e interpretação da variável algébrica nas Equações Algébricas do $1^{\circ}$ grau, para que estes sirvam de âncora para uma nova aprendizagem. Segundo Moreira (2011, p.104),

Precisamente aí é que entra, segundo Ausubel, a utilização de organizadores prévios que servem de "ancoradouro provisório" para a nova aprendizagem e levam ao desenvolvimento de conceitos, ideias e proposições relevantes que facilitam a aprendizagem subsequente. $O$ uso de organizadores prévios é uma estratégia proposta por Ausubel para, deliberadamente, manipular a estrutura cognitiva a fim de facilitar a aprendizagem significativa.

Após a análise do questionário diagnóstico e do préteste, encontrou-se a necessidade de explorar atividades que serão chamadas de "organizadores prévios", já que 70\% dos estudantes afirmou não conhecer a linguagem de programação Scratch. Com relação às Equações Algébricas do $1^{\circ}$ grau, verificou-se dificuldades em relação à interpretação da variável algébrica, sendo que, a questão do pré-teste que envolveu interpretação de dados (Questão 1 do Anexo) apresentou maior quantidade de erros, enquanto a questão envolvendo apenas cálculos (Questão 3 do Anexo) teve o maior número de acertos. Para Moreira (2011, p.30):

Organizador prévio é um recurso instrucional apresentado em um nível mais alto de abstração, generalidade e inclusividade em relação ao material de aprendizagem. Não é uma visão geral, um sumário ou um resumo que geralmente estão no mesmo nível de abstração do material a ser aprendido. Pode ser um enunciado, uma pergunta, uma situação-problema, uma demonstração, um filme, uma leitura introdutória, uma simulação. Pode ser também uma aula que precede um conjunto de outras aulas. As possibilidades são muitas, mas a condição é que precede a apresentação do material de aprendizagem e que seja mais abrangente, mais geral e inclusivo do que este.

Neste sentido, os organizadores prévios foram elaborados para dar significado ao novo conhecimento na estrutura cognitiva do estudante.

$3^{\circ}$ encontro: Organizadores prévios sobre a linguagem de programação Scratch

Realizou-se a apresentação geral do ambiente Scratch, para compreensão da interface e funcionalidade dessa linguagem de programação. Os estudantes manusearam o aplicativo ao final da apresentação.

4" encontro: Utilização do bloco "movimento". Organizadores prévios sobre a linguagem de programação Scratch

Os estudantes foram orientados para o desenvolvimento da atividade na qual deveriam indicar como percorrer o contorno das 4 imagens. Primeiramente numa folha de ofício, posteriormente, deveriam programar no Scratch um ator que fizesse o mesmo percurso. O objetivo desse encontro foi verificar se os comandos propostos pelos estudantes na folha de ofício são válidos quando aplicados no Scratch.

$5^{\circ}$ encontro: Utilização dos blocos "movimento" e "eventos". Organizadores prévios sobre a linguagem de programação Scratch

Os estudantes, em duplas ou trios, deveriam programar o personagem para que este percorresse o caminho até o objeto no final do percurso, nos seguintes labirintos já construídos no programa:

Figura 1 - Labirintos utilizados no desenvolvimento do $5^{\circ}$ encontro

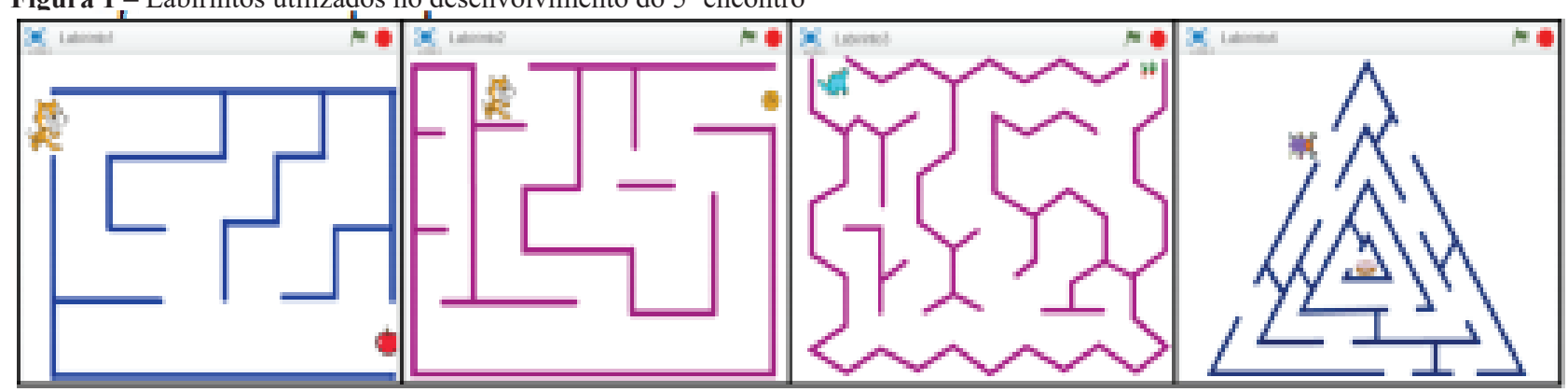

Fonte: Os autores

$6^{\circ}$ encontro: Utilização dos demais blocos do Scratch. Organizadores prévios sobre a linguagem de programação Scratch

Realizou-se exemplos gerais no Scratch, comandos (inclusive se isso, então aquilo), janelas, trajes, palco etc.

Após a realização destas atividades, pode-se perceber que os estudantes estavam familiarizados com o Scratch, sendo que a função do organizador prévio foi alcançada: 
Para Ausubel, a principal função do organizador prévio é a de servir de ponte entre o que aprendiz já sabe e o que ele deveria saber a fim de que o novo material pudesse ser aprendido de forma significativa. Ou seja, organizadores prévios são úteis para facilitar a aprendizagem na medida em que funcionam como "pontes cognitivas". (Ausubel, 1968, p.148).

Ao se inteirar com materiais potencialmente significativos, o estudante, com frequência, manifesta predisposição em aprender. A ansiedade por utilizar tais recursos possibilita a aquisição de novos conceitos, subsunçores necessários à aprendizagem significativa. Percebeu-se neste momento o envolvimento emocional dos estudantes, para integrar o novo conhecimento com o já existente. Desta forma, aproveitando a predisposição, foi realizada a intervenção pedagógica para a aprendizagem do conteúdo de Equações Algébricas do $1^{\circ}$ grau.

\section{$7^{\circ}$ encontro: Utilização do Scratch para a interpretação da variável algébrica}

O objetivo deste encontro foi mostrar aos estudantes como é possível fazer e responder a um questionamento utilizando o software Scratch, fazendo o ator realizar perguntas e lendo a resposta informada pelo usuário. Iniciou-se a abordagem das Equações Algébricas do $1^{\circ}$ grau a partir de situações-problema e utilizou-se os subsunçores relacionados à substituição de um valor numa incógnita e os organizadores prévios sobre a linguagem de programação Scratch, para estabelecer uma interpretação da variável algébrica. Para isto partiu-se da seguinte situação-problema:

Situação Problema 1: "Um homem estava passeando com seu carro e teve um problema, duas rodas de seu carro estragaram. Um mecânico que passava por perto ofereceu ajuda".

Durante a realização da atividade o professor/pesquisador atuou como mediador, e os estudantes foram orientados a desenvolvê-la utilizando a criatividade. Como critério de análise observou-se a modelagem utilizada para a resolução do problema e o uso das estruturas de lógica de programação. Um exemplo de projeto desenvolvido pode ser encontrado no site oficial do Scratch: https://scratch.mit. edu/projects/420656264/, onde os estudantes fazem uso de três atores que interagem entre eles. Observa-se a utilização de estruturas de lógica como por exemplo "espere", "se então" e "senão" e também o uso adequado da variável algébrica no cálculo do valor cobrado pelo serviço. Apesar de apresentarmos apenas um dos projetos como exemplo, todas as programações desenvolvidas neste encontro seguiram este padrão, visto que, houve interação entre os grupos e quando um grupo não conseguia era auxiliado pelos demais.

Observou-se no desenvolvimento do problema as conexões estabelecidas entre as estruturas da linguagem de programação Scratch e o conteúdo de Equações Algébricas, fazendo uso de perguntas e respostas que exigiam cálculos algébricos, utilizando os subsunçores para a aprendizagem subsequente relacionada a interpretação da variável algébrica. Neste sentido, com relação a aprendizagem significativa, esta pode possuir a natureza subordinada, que ocorre quando a informação nova é assimilada pelo subsunçor passando a alterá-lo.

\section{$8^{\circ}$ encontro: Utilizando o Scratch para aprendizagem significativa das Equações Algébricas do $1^{\circ}$ grau através do Construcionismo}

O objetivo deste encontro foi tornar mais significativa a interpretação da variável algébrica, a partir de uma situaçãoproblema apresentada pelo professor/pesquisador. Para isto os estudantes foram orientados a fazer uso do Scratch para desenvolver a seguinte situação:

Situação-Problema 2: "Os estudantes do $8^{\circ}$ ano resolveram confeccionar uma camiseta para a gincana da escola. Sabe-se que a malharia cobrará um valor fixo de $\mathrm{R} \$$ 15,00 e mais $\mathrm{R} \$ 23,00$ por cada camiseta confeccionada. Se nesta turma, 30 estudantes fizerem o pedido da camiseta, quantos reais a turma terão que pagar?"

O professor/pesquisador atuou como mediador e os alunos como protagonistas. Para análise da atividade observouse a modelagem do problema e a utilização de estruturas de programação durante a implementação. Um exemplo de projeto desenvolvido pode ser encontrado no site oficial do Scratch: https://scratch.mit.edu/projects/313880473, que apresenta quatro atores interagindo, com blocos para pergunta e armazenamento da resposta, comandos lógicos "se" "então" e "senão" e o uso correto da variável algébrica para a realização dos cálculos. Apesar da apresentação de apenas um dos projetos como exemplo, todos os estudantes conseguiram utilizar estas estruturas adequadamente.

\section{$9^{\circ}$ encontro: O estudante como protagonista do seu conhecimento - Construcionismo}

Neste encontro, os estudantes, em duplas ou trios, foram orientados a produzirem um projeto baseado numa situaçãoproblema escolhida por eles. Orientou-se para registrar em folha de papel A4 as estratégias e dificuldades que tiveram na construção do projeto. Com esta atividade propiciou-se um ambiente em que o conhecimento não é passado para os aprendizes, mas sim, ao interagir com esse ambiente, "as crianças podem aprender construindo" (Papert, 1993, p.104). O Quadro 1 apresenta-se a descrição de alguns projetos desenvolvidos:

Quadro 1 - Descrição dos projetos desenvolvidos pelos estudantes

\begin{tabular}{|c|c|c|}
\hline Grupo & terística & Link do projeto \\
\hline $\begin{array}{c}\text { Dupla } \\
\text { A }\end{array}$ & $\begin{array}{l}\text { Situação-problema envolvendo } \\
\text { compra e venda utilizando } \\
\text { recursos de pergunta e resposta. }\end{array}$ & $\begin{array}{l}\text { https://scratch. } \\
\text { mit.edu/ } \\
\text { projects/420503188/ }\end{array}$ \\
\hline
\end{tabular}




\begin{tabular}{|c|c|c|}
\hline $\begin{array}{c}\text { Dupla } \\
\text { B }\end{array}$ & $\begin{array}{l}\text { Animação contendo um breve } \\
\text { diálogo entre duas pessoas. } \\
\text { Uso do comando de posição } \\
\text { inicial para que os objetos se } \\
\text { desloquem para a posição que o } \\
\text { programador deseja. }\end{array}$ & $\begin{array}{l}\text { https://scratch. } \\
\text { mit.edu/ } \\
\text { projects/420505184/ }\end{array}$ \\
\hline Trio C & $\begin{array}{l}\text { Uso de } \\
\text { envolvendo o bituação-problema } \\
\text { escola. }\end{array}$ & $\begin{array}{l}\text { https://scratch. } \\
\text { mit.edu/ } \\
\text { projects/315274024 }\end{array}$ \\
\hline Trio D & $\begin{array}{l}\text { Uso de comandos de lógica, } \\
\text { "se", "então", "senão". } \\
\text { Adequação dos tempos para que } \\
\text { os diálogos pudessem acontecer } \\
\text { de maneira correta durante o } \\
\text { desenvolvimento da situação- } \\
\text { problema. }\end{array}$ & $\begin{array}{l}\text { https://scratch. } \\
\text { mit.edu/ } \\
\text { projects/315273624 }\end{array}$ \\
\hline
\end{tabular}

Fonte: Os autores

Os demais projetos possuem abordagem semelhante aos apresentados no Quadro 1. O desenvolvimento dos projetos ocorreu sem a intervenção do professor/pesquisador. Como forma de análise, observou-se o uso correto dos conceitos de programação na modelagem de uma situação-problema escolhida pelos estudantes, através de perguntas e respostas, e principalmente sua conexão com o objeto de conhecimento de Equações Algébricas, no que se refere a interpretação da variável algébrica. Nem todos os projetos conseguiram contemplar com maior profundidade o uso da variável algébrica, como por exemplo o projeto desenvolvido pela Dupla B, porém, nestes casos levou-se em consideração o envolvimento dos alunos na realização da atividade e o uso correto de conceitos de programação e, após a entrega final, o pesquisador apresentou sugestões para melhora dos projetos.

Com relação ao desenvolvimento dos projetos pode-se observar que o papel atribuído aos estudantes é alterado; com efeito, os estudantes têm de se tornar melhores aprendentes (Papert, 1993). Neste contexto, o docente tem a oportunidade de acompanhar o raciocínio que o estudante está utilizando para realizar determinada atividade. E, assim, pode ajudá-lo a interpretar as respostas encontradas e questioná-lo sobre o seu processo mental.

Espera-se que, por meio da programação, os estudantes aprendam com os seus erros. Papert (1980) já defendia que, através da programação, elas desenvolveriam o seu aprendizado como epistemólogos, ou seja, aprendendo a pensar articuladamente. Assim,

Os ambientes intelectuais oferecidos às crianças pelas sociedades atuais são pobres em recursos que as estimulem a pensar sobre o pensar, aprender a falar sobre isto e testar suas ideias através da exteriorização das mesmas. O acesso aos computadores pode mudar completamente esta situação. Até mesmo o mais simples trabalho com a Tartaruga começa com a reflexão sobre como nós fazemos o que gostaríamos que ela fizesse; assim, ensiná-la a agir ou "pensar" pode levarnos a refletir sobre nossas próprias ações ou pensamentos. E à medida que as crianças progridem, passam a programar o computador para tomar decisões mais complexas e acabam engajando-se na reflexão de aspectos mais complexos de seu próprio pensamento (Papert, 1980, p.45).

\section{$10^{\circ}$ encontro: Aplicação do pós-teste}

Aplicação do pós-teste aos estudantes, de modo individual, a fim de procurar evidências da compreensão significativa da variável algébrica. De acordo com Moreira e. Mazini (1982), para procurar evidências de compreensão significativa, a melhor maneira é utilizar questões e problemas que sejam novos. Desta forma, com exceção do número 3, as demais questões do pós-teste foram alteradas em relação ao pré-teste. O uso idêntico da questão 3 tanto no pré-teste quanto nos pós teste refere-se a sua utilização como parâmetro de comparação em relação às demais questões.

\section{Resultados e Discussão}

A fim de auxiliar na identificação da aprendizagem significativa, aplicou-se um pré-teste e um pós-teste, com 5 questões envolvendo o conteúdo de Equações Algébricas do $1^{\circ}$ grau e 6 questões relacionadas à lógica de programação, sendo 5 questões objetivas e 1 discursiva. As questões do pré-teste e pós-teste podem ser conferidas no Anexo deste trabalho.

Com relação as questões envolvendo o conteúdo matemático percebe-se que mesmo após a intervenção com as atividades no Scratch, alguns estudantes ainda mantiveram uma certa resistência com as questões cujos enunciados eram mais elaborados, eles as julgaram difíceis e nem tentaram respondê-las. Neste sentido Moreira e Masini (1982), chamam a atenção para o fato de que se o aprendiz não é capaz de resolver um problema, isso não significa, necessariamente, que ele tenha somente memorizado os princípios e conceitos relevantes à resolução de problemas, pois esta implica também, certas habilidades além da compreensão.

Como por exemplo, na Questão 5 do pós-teste, podese notar que esta não apresenta um nível de complexidade elevado, porém, 7 estudantes afirmaram não saber o que fazer com a incógnita e que não entenderam a questão.

Os Quadros 2 e 3, apresentam o desempenho dos estudantes no pré-teste e pós-testes, respectivamente:

Quadro 2 - Desempenho dos estudantes nas questões de Equações Algébricas do $1^{\circ}$ grau no pré-teste

\begin{tabular}{|l|c|c|c|c|}
\hline & Certa & Incompleta & Errada & Em branco \\
\hline Questão 1 & 2 & 0 & 16 & 6 \\
\hline Questão 2 & 14 & 1 & 5 & 4 \\
\hline Questão 3 & 6 & 5 & 0 & 13 \\
\hline Questão 4 & 0 & 2 & 0 & 24 \\
\hline Questão 5 & 0 & 1 & 1 & 22 \\
\hline
\end{tabular}

Fonte: Os autores

Quadro 3 - Desempenho dos estudantes nas questões de Equações Algébricas do $1^{\circ}$ grau no pós-teste

\begin{tabular}{|l|c|c|c|c|}
\hline & Certa & Incompleta & Errada & Em branco \\
\hline Questão 1 & 12 & 3 & 2 & 7 \\
\hline Questão 2 & 22 & 0 & 2 & 0 \\
\hline Questão 3 & 20 & 1 & 2 & 1 \\
\hline Questão 4 & 2 & 6 & 7 & 9 \\
\hline Questão 5 & 6 & 0 & 11 & 7 \\
\hline
\end{tabular}

Fonte: Os autores. 
As questões envolvendo Equações Algébricas do préteste mostraram que os estudantes possuem dificuldades não somente na interpretação dos enunciados, mas também ao trabalhar com os dados e com as incógnitas presentes nas questões, visto que a quantidade de erros e de questões deixadas incompletas ocorreu em número bem expressivo.

Conforme o Quadro 4, em todas as questões envolvendo conhecimentos de equações algébricas nota-se que houve um aumento significativo na quantidade de acertos, principalmente das três primeiras questões. Além disso, no geral, foi obtido uma redução na quantidade de questões em branco.

Ao fazer a análise entre os dois testes percebe-se que a metodologia foi útil pois os estudantes obtiveram um melhor resultado após as intervenções. Ao deixarem um número menor de questões em branco, demonstram que estão conseguindo relacionar melhor a Álgebra com a interpretação de problemas e a utilização das incógnitas, mesmo sem chegar ao resultado final correto ou no término da resolução da questão. Os avanços na resolução dos problemas utilizando variáveis e métodos de resoluções que fazem uso da Álgebra, remetem a uma boa aceitabilidade da metodologia utilizada na pesquisa.

Pode-se dizer que os estudantes se encontram mais familiarizados com questões que envolvem a utilização de incógnitas e conseguem, uns com mais facilidade do que os outros, resolver as questões propostas. Além disso, ajudam uns aos outros e relacionam os problemas propostos com assuntos que estão acostumados a tratar no dia a dia. Desta forma, percebe-se que o subsunçor inicial relacionado ao cálculo com equações algébricas do $1^{\circ}$ grau interagiu com outro subsunçor, modificando-o e formando inicialmente um novo, que foi se estabilizando e se transformando em outro mais estável, rico e elaborado, neste caso, a interpretação das variáveis algébricas.

As demais questões objetivas, que envolviam lógica de programação, foram classificadas como fáceis antes e após as intervenções, porém no pré-teste, todos os estudantes erraram pelo menos uma das 5 questões. Por outro lado, no pós-teste obteve-se um número significativo de acertos para todas as perguntas. Os resultados são apresentados nos Quadros 4 e 5.

Quadro 4 - Desempenho dos estudantes nas questões objetivas de lógica de programação no pré-teste

\begin{tabular}{|l|c|c|c|c|}
\hline & Certa & Incompleta & Errada & Em branco \\
\hline Questão 6 & 17 & 0 & 6 & 1 \\
\hline Questão 7 & 11 & 0 & 8 & 5 \\
\hline Questão 8 & 14 & 0 & 8 & 2 \\
\hline Questão 9 & 6 & 0 & 12 & 6 \\
\hline Questão 10 & 10 & 0 & 5 & 0 \\
\hline
\end{tabular}

Fonte: Os autores

Quadro 5 - Desempenho dos estudantes nas questões objetivas de lógica de programação no pós-teste

\begin{tabular}{|l|c|c|c|c|}
\hline & Certa & Incompleta & Errada & Em branco \\
\hline Questão 6 & 22 & 0 & 2 & 0 \\
\hline Questão 7 & 24 & 0 & 0 & 0 \\
\hline Questão 8 & 16 & 0 & 2 & 6 \\
\hline Questão 9 & 22 & 0 & 1 & 1 \\
\hline Questão 10 & 21 & 0 & 1 & 2 \\
\hline
\end{tabular}

Fonte: Os autores.
Percebe-se nos Quadros 4 e 5, que houve melhora na habilidade que envolve o subsunçor referente à resolução de problemas relacionados à lógica de programação pois, de forma geral, a quantidade de questões respondidas de maneira incorreta, diminuiu.

Esta variação na quantidade de erros e acertos pode ser justificada pelas intervenções feitas na turma, visto que, em todas as aulas foram utilizados comandos que consistiam numa série de instruções executadas pelo programa especificando a ação que deveria ser concluída.

Em relação ao objeto de conhecimento de Equações Algébricas do $1^{\circ}$ grau, notou-se que os estudantes ainda têm receio de resolver questões cujos enunciados são mais complexos, muitos deles acabaram optando por deixar em branco as questões que consideraram difíceis, porém aqueles que tentaram resolver tiveram uma pequena melhora. No geral, pode-se dizer que os estudantes obtiveram mais acertos nos cálculos e quando cometeram algum erro, conseguiram verificar onde erraram, o que vem de encontro à teoria construcionista do Papert.

Sobre as questões objetivas de lógica de programação, todas tiveram uma redução no número de erros, o que corrobora com o fato de que a linguagem de programação Scratch propicia um ambiente divertido e faz com que a curiosidade e a vontade de aprender de cada estudante sejam estimuladas consideravelmente.

Ambos os testes apresentavam uma questão descritiva, onde os estudantes deviam descrever quais os procedimentos necessários para que Noé conseguisse construir a arca quando ordenado por Deus. O objetivo desta questão era analisar como os estudantes organizam logicamente as etapas necessárias para o desenvolvimento de uma atividade. Nos dois testes, de modo geral, os estudantes elencaram os principais passos. Porém, no pós-teste pode-se perceber diferenças significativas em relação aos detalhes e ordem cronológica na execução dos procedimentos, o que significa que os estudantes conseguiram perceber que, para executar uma tarefa ou operacionalizá-la faz-se necessária a descrição detalhada e cronológica de todas as etapas.

Para a análise dos resultados também se levou em consideração o desenvolvimento dos projetos realizados pelos estudantes. Observou-se a apropriação de conceitos básicos de programação, como por exemplo, os conceitos de sequência (consiste numa série de instruções executadas pelo programa especificando a ação que deve ser produzida), evento (consiste em realizar uma ação quando um acontecimento for analisado), paralelismo (ocorre quando sequências de instruções são executadas ao mesmo tempo), loop (mecanismo que permite executar determinada ação por várias vezes), condicionais (mecanismo que permite que decisões sejam tomadas tendo em vista outras condições pré-existentes) e operadores (mecanismos que dão suporte às operações matemáticas). $\mathrm{O}$ Quadro 6 apresenta a relação dos projetos e os conceitos de programação presentes. 
Quadro 6 - Relação dos projetos e dos conceitos de programação utilizados

\begin{tabular}{|l|l|}
\hline \multicolumn{1}{|c|}{ Projeto } & \multicolumn{1}{c|}{ Conceitos utilizados } \\
\hline 1- Dupla A & Evento, Sequência, Operadores e Condicional \\
\hline 2- Dupla B & Evento, Sequência e Paralelismo \\
\hline 3- Trio C & Evento, Sequência, Operadores e Condicional \\
\hline 4-Trio D & Evento, Sequência, Operadores e Condicional \\
\hline 5- Trio E & Evento, Sequência e Loop \\
\hline 6- Trio F & Evento, Sequência, Operadores e Condicional \\
\hline 7- Trio G & $\begin{array}{l}\text { Evento, Sequência, Operadores, Condicional e } \\
\text { Loop }\end{array}$ \\
\hline 8- Trio H & Evento e Sequência \\
\hline
\end{tabular}

Fonte: Os autores.

Os conceitos mais utilizados foram de evento e de sequência e, como o objetivo era relacionar situações-problema do dia a dia com a Matemática, o conceito de operadores e condicionais também foi bastante utilizado. O conceito de paralelismo foi o menos utilizado. Por se tratarem de projetos que relacionavam o que os estudantes já sabiam com o que lhes foi ensinado tanto em relação às equações algébricas, quanto em relação a lógica de programação, pode-se dizer que a teoria da Aprendizagem Significativa de Ausubel se fez presente neste trabalho, visto que os estudantes fizeram uma conexão entre conceitos préexistentes para a resolução de problemas com os novos que foram desenvolvidos durante as intervenções. E ainda, por serem os estudantes o objeto principal do conhecimento, num ambiente em que eles foram autores e conseguiram relacionar os erros e acertos, a teoria Construcionista de Papert também permeou e deu sentido às atividades.

Tendo em vista a pouca quantidade de computadores e o fato de haver um espaçamento, por vezes maior do que uma semana, entre os encontros, entende-se que há muito para ser melhorado nos próximos estudos. No entanto, não se pode negar que foi observado uma melhora na aprendizagem dos estudantes, pois conseguiram auxiliar uns aos outros sem intervenção, encontravam seus próprios erros e analisavam por várias vezes seus projetos até identificar a melhor maneira de reproduzir a situação desejada, além da melhoria verificada nas questões dos testes aplicados. Isso mostra que, a proposta teve pontos positivos em relação a aprendizagem significativa das equações algébricas do $1^{\circ}$ grau e da lógica de programação.

Ao analisar todo o contexto pode-se dizer que os resultados foram satisfatórios pois possibilitaram o contato e a inserção da tecnologia educacional para estudantes que não estavam tão ligados a essa realidade e instigou nos estudantes o processo criativo ao colocá-los em contato com o ambiente de programação Scratch. Além disso, alguns professores relataram que os estudantes estavam animados e que contavam os dias para os encontros.

Por fim, observou-se um avanço na resolução das questões relacionadas as equações algébricas do $1^{\circ}$ grau, visto que, antes da intervenção os estudantes conseguiam resolver questões que se encontravam explícitas e as que envolviam a interpretação de um problema eram deixadas de lado. Depois da intervenção, alguns estudantes se mostraram mais atentos e mostraram mais motivação para resolver situações-problema, fazendo assim com que o número de questões corretas aumentasse. Desta forma, notou-se que é possível utilizar o software Scratch para auxiliar na Aprendizagem Significativa que tanto se almeja. Conseguiu-se verificar a transformação dos subsunçores prévios, aqueles que os estudantes já possuíam, em subsunçores novos, mais completos, mais detalhados.

\section{Conclusão}

O trabalho teve como ponto de partida a busca de respostas para o problema de pesquisa: avaliar as contribuições do Scratch, através de uma metodologia construcionista, na aprendizagem significativa do conceito de equações algébricas do $1^{\circ}$ grau, para estudantes do $8^{\circ}$ ano de uma escola pública em Lages-SC.

Pode-se dizer que o Scratch é um ambiente virtual que propicia aos estudantes novos conceitos e novas linguagens que auxiliam no processo de ensino e aprendizagem das mais diversas áreas do conhecimento em particular das equações algébricas do $1^{\circ}$ grau.

A coleta de dados teve como objetivos responder duas perguntas: Quais os subsunçores (conhecimentos prévios) dos participantes relativos ao conteúdo de equações algébricas do $1^{\circ}$ grau e lógica de programação? A metodologia utilizada favorece uma aprendizagem significativa do conteúdo de equações algébricas do $1^{\circ}$ grau?

Através do pré-teste pode-se ter clareza quanto aos subsunçores prévios, aqueles conhecimentos que os estudantes já possuíam antes da intervenção. Desta forma, os conhecimentos prévios dos alunos puderam ser analisados. E, no decorrer das atividades verificou-se a transformação dos subsunçores iniciais em subsunçores mais específicos, mais completos e mais ricos em detalhes.

Ao serem apresentados ao Scratch e utilizarem a linguagem de programação, como ferramenta de auxílio diante das dificuldades encontradas na aprendizagem das equações algébricas do $1^{\circ}$ grau, conclui-se que ela propicia um ambiente divertido e faz com que a curiosidade, a criatividade e a vontade de aprender de cada estudante sejam estimuladas consideravelmente. Verificou-se que, para o conteúdo de equações algébricas do $1^{\circ}$ grau, a sua utilização foi de grande valia, possibilitando trabalhar com as teorias do construcionismo e aprendizagem significativa.

Priorizou-se a utilização de problemas do cotidiano para a aprendizagem do conteúdo, e nos projetos desenvolvidos pelos estudantes foram utilizadas situações-problema, que permeavam a realidade e faziam parte de suas vidas.

Desta forma, acredita-se que os objetivos desse trabalho foram alcançados. Como trabalhos futuros, pretende-se utilizar o Scratch para elaboração de sequências didáticas relacionas a outros conteúdos da Matemática. 


\section{Referências}

Aono, A. H., Rody, H. V. S., Musa, D. L., Pereira, V. A., and Almeida, J. (2017). A utilização do Scratch como ferramenta no ensino de pensamento computacional para crianças. In Anais do Congresso da Sociedade Brasileira de Computação

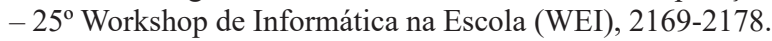

Ausubel, D. P. The psychology of meaningful verbal learning. New York, Grune and Stratton, 1963.

Ausubel, D. P. Educational Psychology: a cognitive view. Nova York, Holt, Renehartand Wintan Inc., 1968.

Da Costa, A. S., De Azevedo, J. M; Rodrigues, M. P., Hauschild, C. A.\& Dullius, M. M. (2018). Investigando as dificuldades apresentadas em álgebra por alunos do oitavo ano do ensino fundamental. Revista Destaques Acadêmicos, 8(4), 159-176. ISSN 2176-3070. http://dx.doi.org/10.22410/issn.2176-3070. v8i4a2016.1224.

Knuth, E.J., Alibali, M. W., Mcneil, N. M., Weinberg, A., Stephens, A. C. (2005). Middle School Students' Understanding of Core Algebraic Concepts: Equivalence \& Variable. ZDM, $37(1), 68-76$.

Moreira, M. A; Masini, E. F. S. (1982). Aprendizagem Significativa: a teoria de David Ausubel. São Paulo: Moraes.

Oliveira, E. C. L. (2009). O uso do software Scratch no Ensino Fundamental: possibilidades de incorporação curricular segundo professoras dos anos iniciais. Belo Horizonte, 106p. (Dissertação de Mestrado Acadêmico em Educação). Pontifícia Universidade Católica de Minas Gerais.
Recuperado em 05 fevereiro, 2020 de: http://www.biblioteca. pucminas.br/teses/Educacao_OliveiraEC_1.pdf

Papert, S. (1980). Mindstorms, Children, Computers and Powerful Ideas. New York: Basic Books.

Papert, S. (1993). Children's Machine: Rethinking School in the Ag of the Computer. New York: Basic Books.

Pedersen, I.F. (2015). What Characterizes the algebraic competence of Norwegian upper secondary school students? Evidence from TIMSS advanced. Int. J. Scie. Mathem. Educn, 13 (Supplement 1), 71-96. doi: https://doi.org/10.1007/ s10763-013-9468-y.

Tahir, S., Cavanah, M., Mitghelmore, M. (2009). A multifaceted approach to teaching algebra: students' understanding of variable. In Tzekaki, M.; Kaldrimidou, M.; Sakonidis, H. (Eds.), Proceedings of PME 33, pp.317-114. Thessaloniki, Greece: Aristotle University,

Usini. S. (2019). O trabalho dos estudantes da escola média com variável algébrica: uma comparação entre a Itália e o México. Educ.Matem. Pesq., 21(3), 119-142. doi: http:// dx.doi.org/10.23925/1983-3156.2019vol21i3p119-142

Warren, E., Trigueros, M., Ursini, S. (2016). Research on the learning and teaching of algebra. In. Gutierrez, A.; Leder, G. C.; Boero, P. (Eds.), The Second Handbook of Research on the Psychology of Mathematics Educatio, pp,73-108. Rotterdam, the Netherlands: Sense Publishers.

Zoppo, B. M. (2016). O uso do Scratch no ensino da matemática. Em: XX Encontro Brasileiro de Estudantes de Pós-Graduação em Educação Matemática - EBRAPEM, Curitiba - PR.

\section{ANEXO \\ Questões do Pré-Teste}

1- (Unicamp-SP) Roberto disse a Amanda: "Pense em um número, dobre esse número, some 12 ao resultado, divida o novo resultado por 2. Quanto deu?" Amanda disse: "15". Roberto, imediatamente, revelou o número original em que Amanda havia pensado. Calcule esse número.

2- Observe a sequência de triângulos:
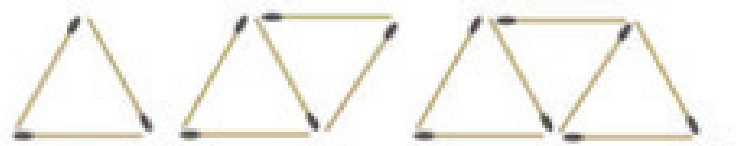

- Complete a tabela com os dados referentes a esta sequência:

\begin{tabular}{|l|l|l|l|l|l|}
\hline Número de Triângulos & 1 & 2 & 3 & 4 & 5 \\
\hline Quantidade de Palitos & & & & & \\
\hline
\end{tabular}

Fonte: autores

- Quantos palitos seriam necessários para fazer 10 triângulos?

3- Calcule o valor numérico da expressão algébrica abaixo para $\mathrm{x}=-2$ e $\mathrm{y}=16$.

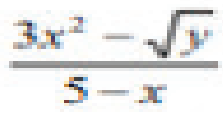

4- A soma dos dois algarismos de um numeral é 6. Trocando os algarismos de lugar, o novo número tem 18 unidades a menos que o número original. Qual é o número original?

5- Sabendo que $A=x^{2}-4 x+4, B=4, C=2 x$ e $D=x+1$, calcule o valor das expressões:

a) A. B

b) $(\mathrm{B}+\mathrm{C})^{2}$

c) $\mathrm{B}+\mathrm{C}-\mathrm{D}$

d) $(\mathrm{C}+\mathrm{D})^{2}$

Sejam PAC MAN 
6- Qual sequência leva o "Pac Man" até o fantasma pelo caminho indicado?
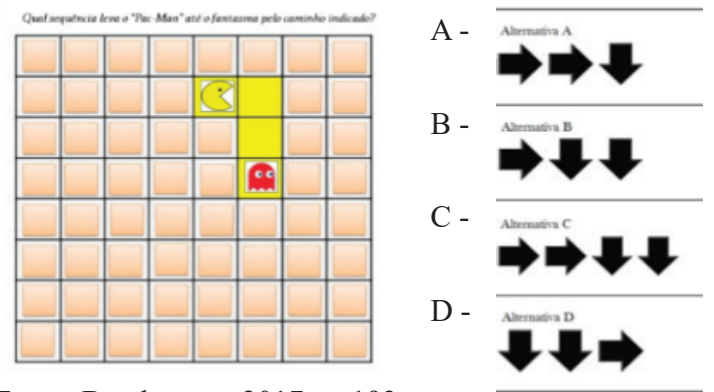

Fonte: Brackmann, 2017, p. 193

7- Para levar o "Pac Man" até o fantasma pelo caminho indicado, qual passo da sequência está incorreto?
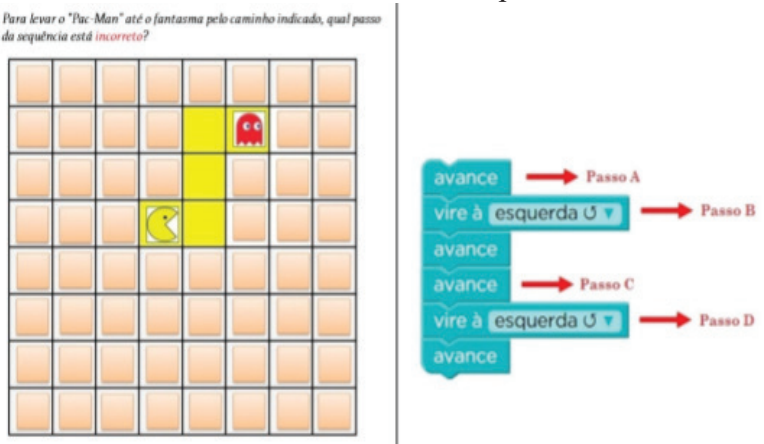

Fonte: Brackmann (2017, p.194);

8- Quantas vezes a sequência abaixo deve ser repetida para leva o "Pac Man" até o fantasma pelo caminho indicado?

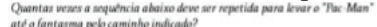

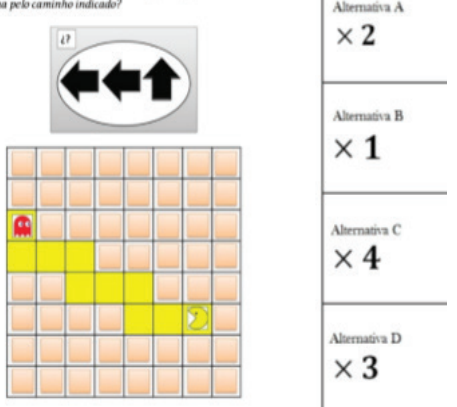

Fonte: Brackmann, (2017)

9- Para que o "Pac Man" chegue até o fantasma pelo caminho indicado, qual passo da sequência está INCORRETO?
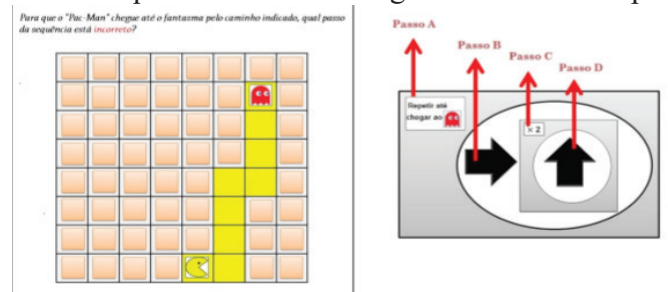

Fonte: Brackmann (2017, p.197).

9- Lucas saiu para passear e encontrou uma surpresa. Organize a história anotando em cada círculo os números de 1 a 4 , tendo em conta a ordem correta em que ocorreram os eventos.
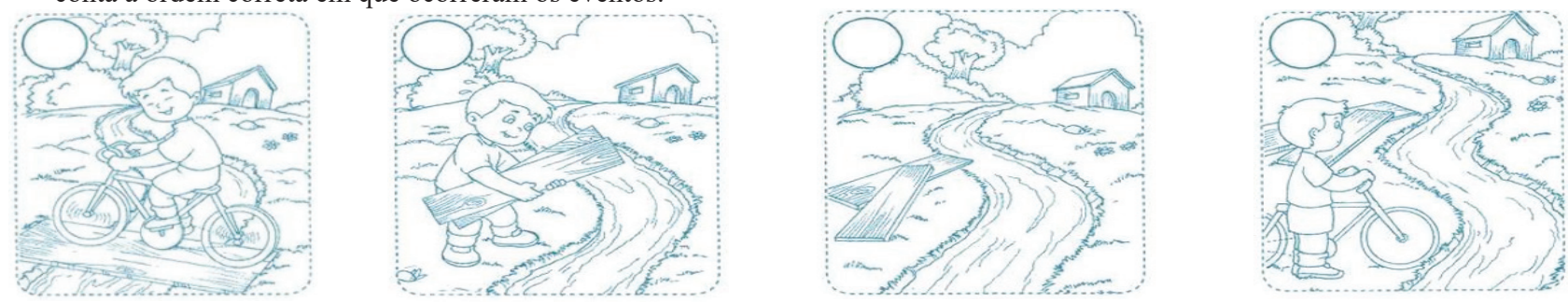

Fonte: Os autores. 
11- Já conhecemos a história de Noé, a quem Deus ordenou a construir uma arca. Observe a imagem e enumere os passos que deve seguir para realizar sua tarefa.

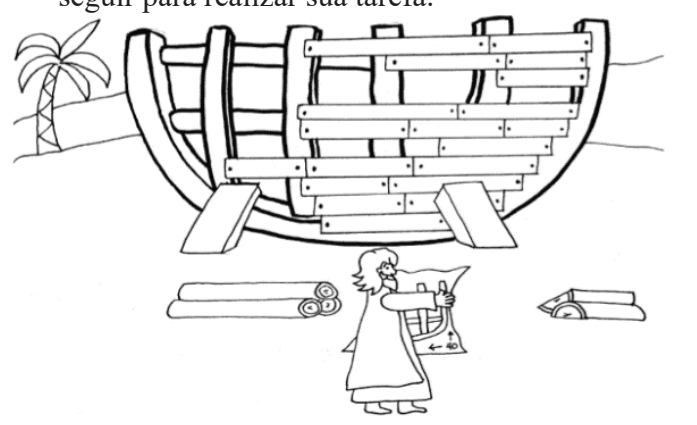

1 -

$2-$

$3-$

4 -

5 -

Fonte: autores

Após ter realizado as atividades propostas no Pré-Teste a seguir, marque com um X o retângulo que expressa o seu grau de dificuldade em cada uma delas:

\begin{tabular}{|c|l|l|l|l|}
\hline Questões/ Nível de dificuldade & Fácil & Médio & Difícil & Muito Difícil \\
\hline 1 & & & & \\
\hline 2 & & & & \\
\hline 3 & & & & \\
\hline 4 & & & & \\
\hline 5 & & & & \\
\hline 6 & & & & \\
\hline 7 & & & & \\
\hline 8 & & & & \\
\hline 9 & & & & \\
\hline 10 & & & & \\
\hline 11 & & & & \\
\hline
\end{tabular}

Fonte: Autores

\section{Questões do Pós-Teste}

1.

Qual a expressão algébrica que representa o perímetro desta figura?

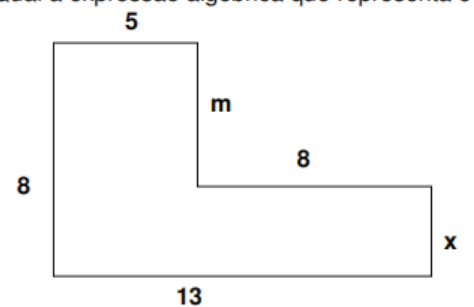

Fonte: Autores

2. Observe a sequência de triângulos:

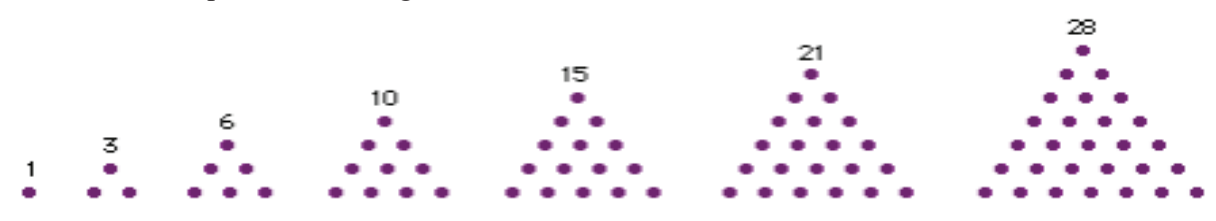

Fonte: Autores

- Complete a tabela com os dados referentes a esta sequência:

\begin{tabular}{|l|l|l|l|l|l|l|l|l|l|l|}
\hline Número de Triângulos & 1 & 2 & 3 & 4 & 5 & 6 & 7 & 8 & 9 & 10 \\
\hline Quantidade de Palitos & & & & & & & & & & \\
\hline
\end{tabular}


3. Calcule o valor numérico da expressão algébrica abaixo para $\mathrm{x}=3$ e $\mathrm{y}=4$.

$$
\frac{3 x^{2}-\sqrt{y}}{5-x}
$$

4. Enzo formou a seguinte figura:

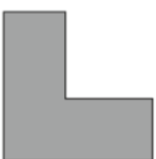

Quais foram as peças que ele usou para formar a figura?
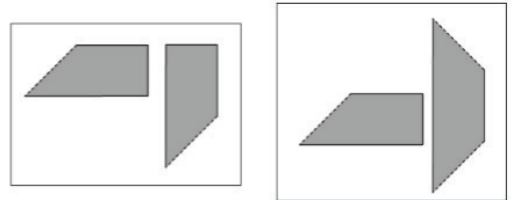

c.

D.
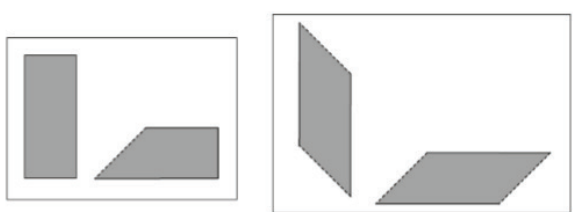

Fonte: Autores

2- Um terreno no qual estão indicadas as medidas dos seus lados tem a forma da figura abaixo ${ }^{14}$.

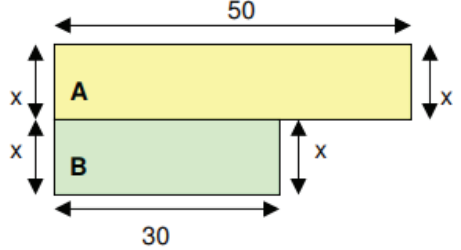

Como você pode observar, o terreno está dividido em dois lotes retangulares A e B

Qual a expressão algébrica que representa:

b) a área do lote $A$ ?

c) a área do lote $B$ ?

d) a área total do terreno?

5.

Fonte: Autores

Sejam PAC MAN 3 e FANTASMA, ic responda:

6. Qual comando está faltando na sequência para levar o "Pac Man" até o Fantasma caminho indicado?

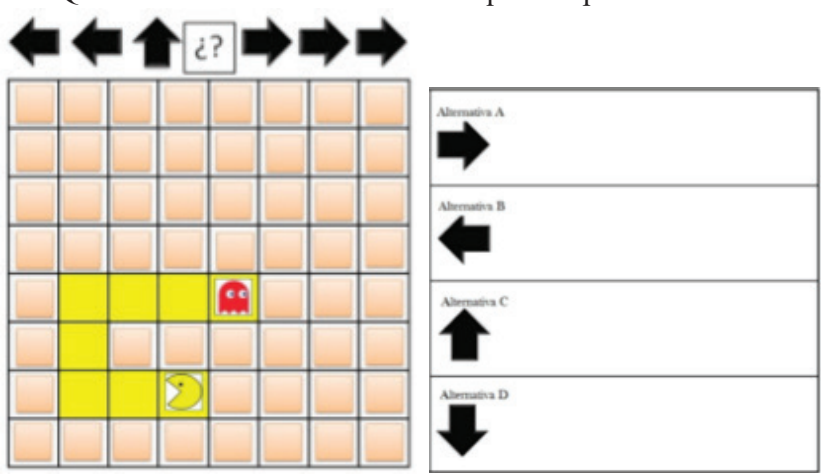

Fonte: Brackmann, 2017, p. 193 
7. Qual sequência leva o "Pac Man" até o fantasma pelo caminho indicado?

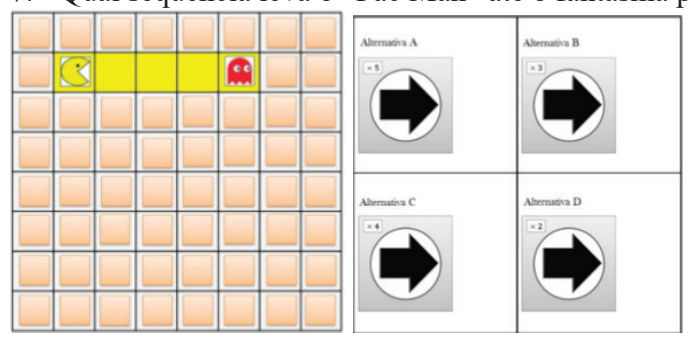

Fonte: Brackmann, 2017, p. 194

8. Para que o artista desenhe uma vez o seguinte retângulo (50 pixels de largura e 100 pixels e altura), qual passo da sequência está INCORRETO?

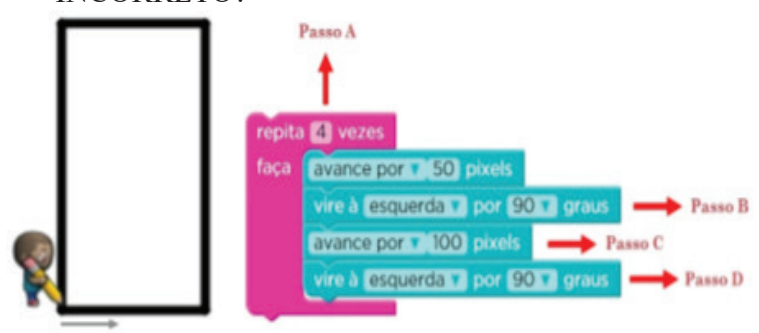

Fonte: Brackmann, 2017, p. 194

9. Qual sequência leva o "Pac Man" até o fantasma pelo caminho indicado?
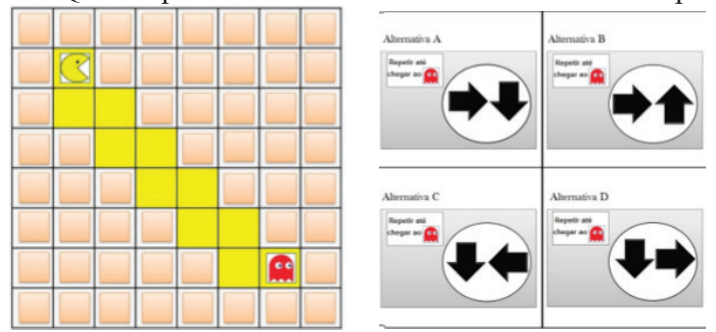

Fonte: Brackmann, 2017, p. 196

10. Observe as seguintes imagens e escolha a sequência correta de como os fatos aconteceram.
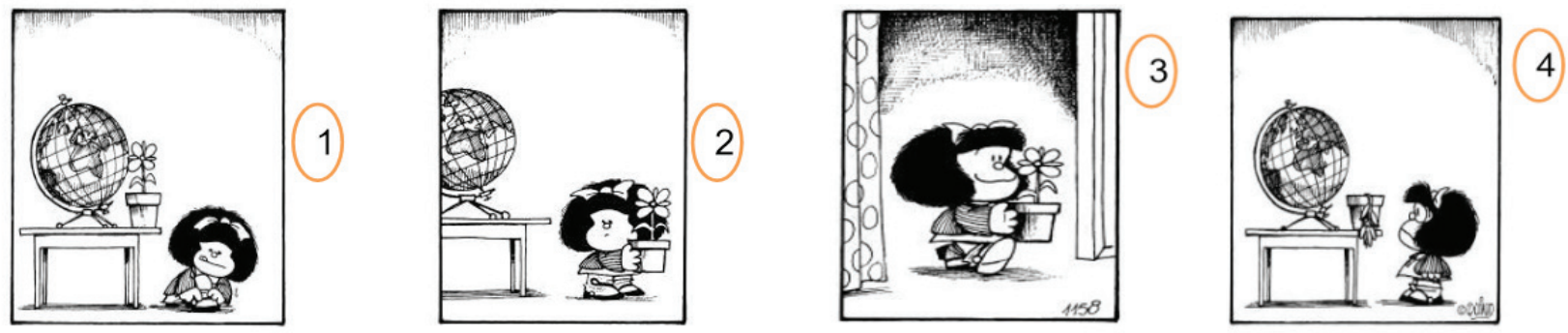
A. 1-2-3- 4
B. $3-1-2-4$
C. 4- 2-1-3
D. $3-2-1-4$

Fonte: Autores

11. Já conhecemos a história de Noé, a quem Deus ordenou a construir uma arca. Observe a imagem e enumere os passos que deve seguir para realizar sua tarefa.

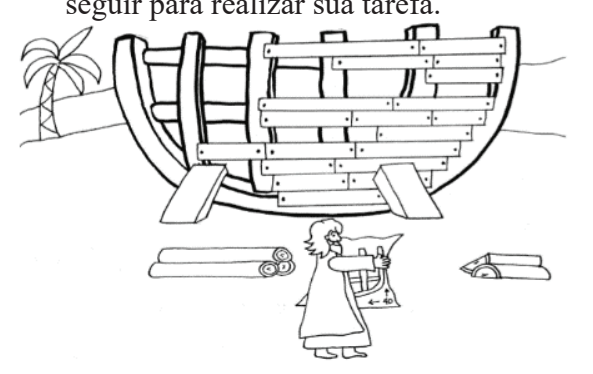

$$
\begin{aligned}
& 1- \\
& 2- \\
& 3- \\
& 4- \\
& 5-
\end{aligned}
$$$$
3-
$$ 
Após ter realizado as atividades propostas no Pré-Teste a seguir, marque com um X o retângulo que expressa o seu grau de dificuldade em cada uma delas:

\begin{tabular}{|c|l|l|l|l|}
\hline Questões/Nível de dificuldade & Fácil & Médio & Difícil & Muito Difícil \\
\hline 1 & & & & \\
\hline 2 & & & & \\
\hline 3 & & & & \\
\hline 4 & & & & \\
\hline 5 & & & & \\
\hline 6 & & & & \\
\hline 7 & & & & \\
\hline 8 & & & & \\
\hline 9 & & & & \\
\hline 10 & & & & \\
\hline 11 & & & & \\
\hline
\end{tabular}

Fonte: Autores 